\title{
Factors Affecting Women Participation in Leadership Position: The Case of Debre Markos City Administration
}

ISSN: 2311-8636 (Print)

ISSN: 2312-2021 (Online)

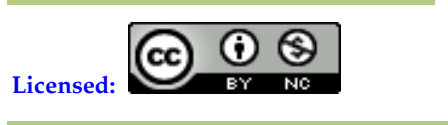

Source of Support: Nil

No Conflict of Interest: Declared

Email for correspondence:

gamekonnenn@gmail.com

\section{Genet Bekele Yemenu}

Department of Management, College of Business and Economics, Bahir Dar University, ETHIOPIA

\section{ABSTRACT}

Women face multi -faceted challenges to participate in management position due to different factors. The purpose of this research is to investigate factors that affect participation of women in leadership position. . And for ward some possible suggestion for the challenges identified through this study. The study was descriptive in nature and survey solving method was used in data gathering. Data used in this research was mainly primary and secondary data as well, quantitative and qualitative types was incorporated. The data was collected by interviewing and conducting questionnaires. The study revealed that the current status of women participation was low in number in city administration and there are different factors that affect women's participation in leadership position. The factors which contribute for women's low participation in leadership positions were categorized under three main factors: societal, institutional (organizational) and individual factors. It was observed those women's career advancements are not affected by one factor alone but a combination of different factors. From these factors the research found that three factors (institutional socio culture and individual) have decisive contribution for low participation of women in leader ship position. According to the respondents, there are institutional (organizational), socio culture and individual factors that have major contribution to the low representation of women in the leadership positions of governmental organization respectively by proper implementation of women policies in the organization, equal treatment during assignment leadership position, providing training to build women's capacity and creating awareness to the society that women capable for leadership position the researcher recommends that women should be encouraged and supported in order to compete on leadership positions.

Keywords: leadership, participation, Debre Markos City, Administration, leadership position

\section{INTRODUCTION}

Ethiopian context, Ethiopia is one of the countries which signed the international declarations affirming the legal rights and equality of men and women. In addition to this it has incorporated such a point in the Constitution in Article (9) which states that "All international agreements ratified by Ethiopia are an integral part of the law of the land" (Constitution of the FDRE, 1995, p. 79). 
The nationwide policy on women which is formulated in 1993 aimed to address gender in equality in the social, economic and political aspects and to create strategies \& policies on gender issues of the country particularly on women`s empowerment. However, the practice implies low participation of women especially in leadership positions. For instance, women leaders' representation in the was as follows: Federal parliament 27.8\%, Ministerial level 13\%, State Ministers 8.3\%, Commissioners 25\% and Ambassadors 12.7\%. Even though, Ethiopian government had issued different legal frame works that can help women to have equal access in decision making activities, things set back in implementation.

Similarly, the situation of women in Debre Markos is not much different from those of women in many parts of Ethiopia. Women in Debre Markos have been subjected to various forms of gender-based discrimination under traditional customary rules and practices which in many ways have had impacts on economic, political, and social status of women in the city. The under representation of women and their low participation in general and in the leadership in particular is caused by several factors, social-cultural, institutional, and individual factors. The success of attaining the outcomes of women's active participation depends on those factors that hinder women from taking leadership position.

\section{Statement of the Problem}

As far as leadership is concerned, both men and women are expected to participate in. However, studies have shown that women are underrepresented in leadership position. (Thornton, 2012, pp, 13) Even though, women make up half of the adult population, and often contributed much more than their share to society, inside and outside the house, they are frequently excluded from position of power. This situation has affected women in many ways and results violation of their rights (Thornton, 2012).

The low participation of women in any aspect of life has become an issue in all over the world (Thornton, 2012). Furthermore, we can assure this fact by taking women's leadership position in Debre Markos city administration, the place where this research was conducted. According to the data obtained from Debremarkos city administration civil service department $20091^{\text {st }}$ quarter report that currently there are 80 political leaders and 44 process owners. In the city administration there are totally 124 leader positions. $23(18.5 \%)$ of the positions are handed by women while the101 (81.5) position are predominantly occupied by men. From the above facts we can say that the participation of women in leadership position is less. Women are underrepresented even though they constitute half of the population. The underrepresentation of women in leadership position of any kind affects women negatively in many aspects: economically, socially and psychologically. This result in poor contribution for development, in equality of women and men, depression and de motivation of women for work, absence of role models for women etc. Thus this study tries to find out the factors that affect participation of women in leadership position in East Gojjam zone particularly in Debre Markos city administration.

\section{Objective of the Study}

The main objective of this research is to assess factors that affect women's participation in leadership positions in the Debre Marko City Administration. The specific objectives of the study are to:

- Assess the current status of women participation in leadership.

- To assess the socio culture factors that effect on women leadership involvement. In Debre Markos city administration. 
- To investigate the organizational factors those hinder participation of women in leadership position in Debre Markos city administration.

- To assess the personal factors that influence women leadership participation in Debre Markos city administration.

\section{LITERATURE REVIEW}

In any society, individuals play some roles, and one of such is the role of a leader. Usually a leader is the one who bears the biggest responsibility; it is the most powerful role in an organization. The most common opinions about leaders are that they deal with everything and give directions: leaders have power, all the gains and pursuing an objective is only an object of interest of a leader. Other employees are called followers, even if they are leaders of a lower group or fulfill some duties of a leader. The concept of leadership involves relationships deeply rooted in social settings (Bryman, 1996) requiring leadership theory and research to integrate leader attributes and behaviors within contextual aspects of leader emergence and effectiveness (Yukl, 2006).

According to the feminist theory, which beliefs in equality of men and women there are so many factors that hinder women from advancing to leadership position (Nzomo, 1995) and from those factors some of them are described as follows

Top positions are suitable for men not for women. Accordingly the role of women is to be mothers, care givers and nurtures. Qualities associated with top level administration, namely leadership, intellectual achievement, competence, independence and competition are for men (Hoobler, 2011). The emergences of stereotypes, which lead to belief that women and men are different, have blocked women carrier development including leadership. Socio cultural factors are society's perception which are constructed gender based role is very serious in preventing women from leadership position. A research finding in Kenya, revealed, that women is occupying a small percentage of senior leadership position due to the impact of socio-cultural factors (OSSREA, 2004)

A significant social feature resides in the double if not triple responsibilities of women: In most countries, women are perceived to have primary responsibilities as wives and mothers. But in many cases, either as a result of a preference for personal development, or out of sheer economic necessity, women also go out to work in the employment market. Managing these different occupations and their consequent responsibilities is no easy task for anyone man or woman (Willis, 1991).

In relation to this, as the study conducted by Netsanet (2013), confirms that the negative attitude of organization who hire women take the main share of becoming barrier to women participation in school leadership. Some organizations, when they select employees for managerial positions, because of negative stereotyping, use selection criteria that completely exclude women from the competition and favor the participation of men. According to the study stereotyping, i.e. assuming that male leaders are 'better' than female leaders and women are 'inferior' to males, were also the major negative stereotyping barriers that marginalized women not to become leader in the organization.

Gender stereotypes can be described as the characteristics, attitudes, values and behaviors that society specifies as appropriate for the particular gender. The differences may have arisen not just from biological differences but also from sex role socialization during childhood and the way in which men and women develop psychologically. Gender 
stereotypes have consistently demonstrated that men are generally seen as more agent and more competent than women, while women are seen as more expressive and communal than men (Ginige, 2007).

Women are not the same as men; they have particular biological functions that make them different, which in turn make their work experiences different. To this end, treating men and women the same has effectively created a systemic form of indirect discrimination for women. Mbugua (2007) asserts that pregnancy is a workplace issue that starts well before conception and ends long after birth. It is impossible to separate pregnancy and family responsibilities.

In Ethiopia context Eleny (2013) conducted a study on the factors that affect performance of women manager in Ethiopia ministry of civil service. The finding of the study indicates that the major factors which affect the performance of women leadership in ministry can be recapped as; personal structural and cultural factor, This are reflected through socio cultural attitude, legal barrier, absence of enabling environment, lack of right educational back ground, lack of skill and self-confidence and conflict between career and family responsibilities or over burden of family responsibility are the major one.

\section{Research Methodology}

\section{Population and Sampling Design}

The target population for this study was female employees and leaders of Debre Markos City Administration. There are 908 female employees 23 female leaders in the public sector of the town. For manageability the sample contains $20 \%$ the respective groups of population (female employees). So the study contains 191 employees in the public sector of the town.

Likewise, there are 23 female leaders in the town. Since the population of female leaders is too small the researcher uses census (purposive) sampling was employed to take the required respondents of the part sampling. Thus the sampling size was all 23 female leaders. Consequently, there were 214 respondents form two cluster.

\section{Data Collection Methods}

The questionnaires (Both closed ended and open ended) were used as an instrument of data collection. For this study two types of self- administrating questionnaires were used to collect relevant information from female political leaders and process owners. Questionnaire were prepared and distributed to female experts. In this study the questionnaire were used to extract data embedded deep in participants mind or their attitudes, feelings or reactions. The questionnaire consist both closed and open ended questions in order to collect the necessary information from the participants. Responses collected through questionnaires were summarized, coded, classified and then fed into a computer and analyzed using statistical packages for SPSS Version 20 Software.

\section{Method of Data Analysis}

After the collection of the necessary data it is editing, coding and classifying according to pre-defined criteria. Quantitative and qualitative data analysis techniques were employed. That information gathered using closed ended items is organizing and analyzing using quantitative methods and qualitative analysis also used to explain data obtained through interview. The questions are categorized into several groups, where each group of questions is analyzing separately to indicate and explain the factors which affect women participation in leadership. 
Descriptive statistical tools such as percentages, mean, standard deviation and frequencies for data collection through questionnaires, whereas description of finding were used for data collection through interview.

\section{DATA ANALYSIS}

To collect the data through questionnaire, 191 set of questionnaires were distributed in Debre Markos and 186 of questionnaires were returned back with completely filled, representing $97.3 \%$ response rate. Among the questionnaires distributed $2(1.04 \%)$ of the respondents fail to return the questionnaire whereas $3(1.5 \%)$ of the returned questionnaires were incorrectly completed are discarded from the analysis. The returned questionnaires hoped sufficient to analyze the data with it. In addition to questionnaires, interview was conducted with some selected political leader, process owners.

\section{Women's Current Participation in Leadership}

The following table shows that for current women's leadership position rated by respondents

Table 1: Women's Current Position in Leadership

\begin{tabular}{|c|l|c|c|c|c|c|}
\hline No & Item & \multicolumn{4}{|c|}{ Rating \% } \\
\cline { 3 - 7 } & & 5 & 4 & 3 & 2 & 1 \\
\hline 1 & Women have equal share in leadership & 2 & 13 & 20 & 108 & 43 \\
\hline 2 & Balance between assignment of men and women in leadership position & 6 & 13 & 41 & 76 & 50 \\
\hline 3 & Women leaders are influential during budgeting resources & 8 & 15 & 50 & 76 & 37 \\
\hline 4 & Women leaders can administer and use allocate resources & 74 & 102 & 4 & 6 & \\
\hline 5 & Women leaders are influential in gender and other social issues & 2 & 15 & 24 & 62 & 83 \\
\hline 6 & Women leaders are represented in formulating and planning policies & 2 & 6 & 15 & 92 & 71 \\
\hline 7 & Women leaders involve in public issues & 2 & 6 & 15 & 92 & 71 \\
\hline 8 & Women leaders exercise real power to make decision in their position & 20 & 13 & 11 & 78 & 64 \\
\hline 9 & Women leaders get political representation & 12 & 26 & 41 & 71 & 36 \\
\hline 10 & Women Leaders get promotion to senior position & 8 & 16 & 22 & 66 & 74 \\
\hline
\end{tabular}

Note $5=$ strongly agree $4=$ moderately agree $3=$ neutral $2=$ moderately disagree 1 =strongly disagree

As shown in the table above one can understand that women have unequal position in various aspects in the organization compared to their counterpart. According to the respondents the result revealed that women's have unequal share in leaders ship. More than $80.7 \%$ of the respondents disagree on the item 1 which is related with an equal share of women leadership. In addition the response of the respondent an indicated in real power to make decision in their position. Furthermore, the table also shows that women are unable to administer and allocate resource item and they are no influential in different gender and social issues.

\section{Factors Affecting Women Participation in Leadership Position}

There are number of factors that influence women's participation in leader ship position. The following are factors that constrain woman participation in leadership position in public organization. Some of them are social culture, individual problems institutional factors are summarized in descriptive statics and one sample test. 


\section{Socio- Cultural Factors}

The table below shows that the impact of social culture factors on women participation in leadership position in Debre Markos city administration.

Table 2: Socio Cultural Factors Affecting Women Participation in Leadership Position Rated by Respondents

\begin{tabular}{|c|l|c|c|c|c|}
\hline No & \multicolumn{1}{|c|}{ Mean } & S D & $\begin{array}{c}\text { P. } \\
\text { Value }\end{array}$ & $\begin{array}{c}\text { Rank of } \\
\text { severity }\end{array}$ \\
\hline 1 & Societal believe of women having poor leadership skill & 3.8925 & .74923 & .000 & 6 \\
\hline 2 & $\begin{array}{l}\text { There is mistrust on women leadership from the } \\
\text { community }\end{array}$ & 4.4570 & .63312 & .000 & 1 \\
\hline 3 & $\begin{array}{l}\text { Societal belief of women cannot successfully exercise } \\
\text { their leadership responsibility }\end{array}$ & 3.8710 & .93260 & .000 & 7 \\
\hline 4 & Women lack of acceptance by the society & 3.9677 & .99133 & .000 & 5 \\
\hline 5 & Societal belief of women lack decision making capacity & 4.0753 & .92106 & .000 & 4 \\
\hline 6 & $\begin{array}{l}\text { Lack of cooperation of the society to women leaders } \\
\text { Societal belief of women leaders have low problem } \\
\text { solving capacity }\end{array}$ & 4.1075 & .64870 & .000 & 3 \\
\hline
\end{tabular}

Source: field survey

That is the extent of mistrust of the society on woman's leadership above the expected mean value (3) in which $\mathrm{M}=4.45 . \mathrm{SD}=.63$. This implies that due to the mistrust of the community women are not recommended to be a leader. Even, after they become a leader they have challenge to participate actively indecision making process. There was statically significance mean difference $\mathrm{b} / \mathrm{n}$ the extent of lack of cooperation from the society to women leaders and the expected mean value (3). That is the extent of lack of cooperation from the society to women leaders is above the expected mean value ( $\mathrm{M}=4.32 \mathrm{SD}=.61)$. This implies that level of cooperation of the society were low to woman leaders which affect the participation of women in leader ship position. So it is possible to say that woman excluded themselves from the leadership because of lack of cooperation from the society.

In the same way there was statically significance mean difference between societies believe of women leaders have low problem solving capacity and expected mean value (3). That is the extent of social believes on women's not having decision making capacity is above the expected mean value $(\mathrm{m}=4.10,5 \mathrm{D}=.64)$. This implies that according to social believe woman leaders have low decision making capacity that causes for low participation woman leadership position. Similarly there was statically significance mean difference between the extent of social believes of women can't successfully exercise their leadership responsibility and the expected mean values. That is the extent of the social believes of women can't successfully exercise their leadership responsibility is above the expected mean value $(M=4.07, S D=0.92$.) This indicates that social believes of woman can't successfully exercise their leadership responsibility was also another factor that determines the participation of women in leadership position.

Moreover, which believes of qualities of associated with top level administration; leadership intellectual achievements, competence independency and compaction are for men and have blocked women carrier development including leadership (Hoobler, 2011). 


\section{Personal Factors}

This factor focuses on respondent's opinion related to women attitude towards them. As motioned indifferent resources women themselves are not continent to become a leader. This part attempts to find out whether it is supported by the respondents or not.

Tables 3: Personal Factor Affecting Women Participation in Leadership Potation Related by the Respondents

\begin{tabular}{|c|c|c|c|c|c|}
\hline No & Item & Mean & S.D & $\begin{array}{c}\text { P. } \\
\text { valus }\end{array}$ & $\begin{array}{l}\text { Rank of } \\
\text { severity }\end{array}$ \\
\hline 1 & $\begin{array}{l}\text { Personally women having low self-esteem for } \\
\text { leadership }\end{array}$ & 3.8871 & 1.18693 & .000 & 7 \\
\hline 2 & $\begin{array}{l}\text { Personally women have low self- confidence for } \\
\text { leadership }\end{array}$ & 4.0538 & 1.04354 & .000 & 6 \\
\hline 3 & $\begin{array}{l}\text { Personally women have low self- assertiveness for } \\
\text { leadership }\end{array}$ & 4.0538 & .91670 & .000 & 5 \\
\hline 4 & Women leaders have low leadership knowledge & 4.1774 & 1.12741 & .000 & 3 \\
\hline 5 & $\begin{array}{l}\text { Women personally have low emotional stability for } \\
\text { leadership }\end{array}$ & 3.8441 & 1.35263 & .000 & 8 \\
\hline 6 & $\begin{array}{l}\text { Women personally lack commitment to accept } \\
\text { leadership }\end{array}$ & 4.3441 & .84463 & .000 & 1 \\
\hline 7 & $\begin{array}{l}\text { Women have low intrinsic motivation to solve problem } \\
\text { in leadership position }\end{array}$ & 3.7903 & 1.23643 & .000 & 9 \\
\hline 8 & Women lack of skill for dealing challenges & 2.7688 & 1.91305 & .101 & 10 \\
\hline 9 & $\begin{array}{l}\text { Personally women have poor educational back ground } \\
\text { for leadership }\end{array}$ & 4.2796 & .81028 & .000 & 2 \\
\hline 10 & $\begin{array}{l}\text { Personally women have low aspiration to accept } \\
\text { leadership }\end{array}$ & 4.1344 & .86880 & .000 & 4 \\
\hline
\end{tabular}

The result reveal that there was statically mean different between the extent of women personality lacking commitment to accept leadership position and the expected mean value (3).That is the extent of women personally lacking commitment to accept leadership position is above the expected mean value ( $\mathrm{M}=4.34$ and $\mathrm{SD}=.84)$. This implies that women have low commitment to accept leadership position and results low participation of women in leadership position. Similarly there was statically significance mean difference $b / n$ the extent of women personally having poor educational back ground for leadership position and the expected mean value(3). That is the extent of women personally having poor educational back ground for leadership position is above the expected mean value $(\mathrm{M}=4.22 \mathrm{SD}=.81)$. This implies that low educational back ground had its in great role for the low participation women in leader ship position.

There was statistically significant mean difference between the extents of women having low leadership knowledge and the expected mean value( 3).That the extent of women having low leadership knowledge is above the expected mean value( $M=4,17 \mathrm{SD}=1.12)$. Therefore, leads to the low participation of women in leadership position.

There was statistically significant mean difference between the extents of women personally having low aspiration to accept leadership position and the expected mean value. That is the extent of woman personally having low aspiration to accept leadership position is above the expected mean value $(\mathrm{M}=4.13, \mathrm{SD}=.86)$. This implies that having low aspiration of women to accept leadership position was another factor for the low 
participation of women to accept leadership position. In the same way there was statistically significant mean different between the extents of women personally have low self-assertiveness for leadership and the expected mean value. That is the extent of women personally having low self-assertiveness for leadership is above the expected mean value $(\mathrm{M}=4.03, \mathrm{SD}=.91)$. This implies that women's have had low self-assertiveness to participate in leader ship position. There was statistically significant mean difference between the extents of women personally have low self-confidence for leadership and the expected mean value. That is the extent of woman personality having low self-confidence for leadership is above the expected mean value $(M=4.05, S D=1.04)$. This implies that lack of self-confidence was another factor for the low participation of women in leadership position.

\section{Organizational Factors}

Policies strategies and organizational set up were the expected factors that contribute to low participation of women leadership. The respondents rated the item under this section in the fallowing manner. Organizational factors affecting women participation in leadership position rated by respondents.

Table 4: Organizational Factors that Affect Women Participation for Leadership Position were reported by the Respondents

\begin{tabular}{|c|l|c|c|c|c|}
\hline No & Item & Mean & S.D & $\begin{array}{c}\text { P. } \\
\text { valus }\end{array}$ & $\begin{array}{c}\text { Rank of } \\
\text { severity }\end{array}$ \\
\hline 1 & $\begin{array}{l}\text { Women face un equal treatment during assignment of } \\
\text { individuals in leadership position. }\end{array}$ & 4.2043 & .58001 & .000 & 3 \\
\hline 2 & There is no supportive work system for women leaders & 3.9731 & 1.01039 & .000 & 8 \\
\hline 3 & $\begin{array}{l}\text { Employees of organization are not cooperative for } \\
\text { women leaders }\end{array}$ & 3.9892 & .77102 & .000 & 7 \\
\hline 4 & $\begin{array}{l}\text { Organizations do not provide training to build women } \\
\text { capacity }\end{array}$ & 3.9140 & .97710 & .000 & 9 \\
\hline 5 & $\begin{array}{l}\text { Organizations do not allocate the required budget to } \\
\text { improve women participation in leadership }\end{array}$ & 4.1237 & .86417 & .000 & 6 \\
\hline 6 & $\begin{array}{l}\text { There is no monitoring system to improve women } \\
\text { participation in leadership }\end{array}$ & 3.8978 & 1.01624 & .000 & 10 \\
\hline 7 & $\begin{array}{l}\text { There is glssceiling syndromes during implementation of } \\
\text { women policies }\end{array}$ & 3.7581 & 1.26942 & .000 & 11 \\
\hline 8 & $\begin{array}{l}\text { There is no recognition of women for their leadership } \\
\text { performance }\end{array}$ & 4.5000 & .54277 & .000 & 2 \\
\hline 9 & $\begin{array}{l}\text { Lack of organization's commitment to involve women in } \\
\text { to senior leadership position }\end{array}$ & 4.1667 & .98044 & .000 & 4 \\
\hline 10 & $\begin{array}{l}\text { Unfairness of working situation to participate women in } \\
\text { leadership position }\end{array}$ & 4.1559 & .83981 & .000 & 5 \\
\hline 11 & $\begin{array}{l}\text { There is no proper implementation of women policy for } \\
\text { leadership }\end{array}$ & 4.6667 & .49502 & .000 & 1 \\
\hline
\end{tabular}

The result reveals that there was statistically mean difference between the extents of no proper implementation of women policy for leadership and the expected mean value (3). That is the extent of no proper implementation of women policy for leader ship is above the expected mean value $(\mathrm{M}=4.66, \mathrm{SD}=.49)$. This implies that there was no proper implementation of women policy in the organization to enhance the participation of women in leadership position or these findings illustrated that even if there were gender 
sensitive plans and strategies that encouraged women participation in leadership position, the officials and stakeholders at different hierarchy were not committed to implement those policies and strategies effectively so as to increase the number of women leaders in government organization. In the same way there was statistically significant mean difference between the extents of no recognition of women for their leadership performance and the expected mean value. That is the extent of no recognition of women for leadership performance is above the expected mean value $(\mathrm{M}=4.50, \mathrm{SD}=.54)$. This implies that there was low recognition of women for their leadership performance. This is another point that causes the low participation of women in leadership position. There was also statistically significant mean different between the extents of treatment of women are unequal during assignment of individuals in leadership position and the expected mean value. That is the extent of treatment of women were unequal during assignment of individuals in leadership position is above the expected mean value $(M=4.20, S D=0.58)$. This implies that there was unequal treatment of women during the assignment of individuals in leadership position. This result shows that low participation of women in leadership position.

There also statistically significant mean differences between the extents of organizations do not provide training to build women capacity and the expected mean value. That is the mean extent of organizations do not provide training to build women's capacity is above the expected means value $(M=3.91 S D=0.97)$. This implies that organizations do not provide training to build women's capacity to participate in leadership position. There was also statistically significant mean difference between the extents of extent of not having supportive work system for women leaders and the expected mean value. (M= 3.97, $\mathrm{SD}=1.01$ ). This implies that there was low supportive work system for women's to increase the number of women in leadership position. Similarly there was statistically significant mean difference $b / n$ the extents of lack of monitoring system to improve women's participation in leadership and the expected mean value. That is the extent of lack of monitoring system to improve women's participation in leadership position is above the expected mean value $(\mathrm{M}=3.89 .09 \mathrm{SD}=1.01)$. This implies that was lack of monitoring system to improve women's participation in leadership position. And also there was statistically significant mean difference between the extent glassceliling syndromes during the implementation of women's policy is above the expected mean value $(\mathrm{M}=3.75 .14, \mathrm{SD}=1.26)$. This implies that there were glasses ceiling syndromes during the implementation of women's policy which affect the participation of women in leadership position

\section{Compares of Factors Affecting Women Participation in Leadership}

Even though all the social-culture, individual and institution factors affect the participation of women in leadership position this not necessary mean all factors have equal impact on women's participation in leader ship position. Coefficient are calculated as standardized beta and unstandardized beta which accounts for standard error. Social cultural factor Beta (.23) personal factor (.25) organizational factor (.42). To know the contribution of social cultural factor, personal factor and organizational factor we have to calculate the correlation coefficient of the factors affecting women participation on leadership position and we have to multiply with standardized coefficient beta. So the following table summarized the contribution each independent variable (factor) on women leadership position. 
Table 5: Summary of individual contribution of the factors which included in the research on women's leadership position

\begin{tabular}{|c|c|c|c|c|}
\hline $\begin{array}{c}\text { Factors affecting } \\
\text { women } \\
\text { participation on } \\
\text { leadership position }\end{array}$ & $\begin{array}{c}\text { Correlation } \\
\text { coefficient fact } \\
\text { Ors on women } \\
\text { participations }\end{array}$ & $\begin{array}{c}\text { Standardized } \\
\text { beta }\end{array}$ & $\begin{array}{c}\text { Product of } \\
\text { standardized beta } \\
\text { and Correlation } \\
\text { coefficient }\end{array}$ & $\begin{array}{c}\text { Contribution } \\
\text { of each factor }\end{array}$ \\
\hline Personal factor & $.55^{* *}$ & .23 & $.55 \times .23 \times 100$ & 12.65 \\
\hline $\begin{array}{c}\text { Social -cultural } \\
\text { factor }\end{array}$ & $.57^{* *}$ & .25 & $.57 \times .25 \times 100$ & 14.25 \\
\hline $\begin{array}{c}\text { Organizational } \\
\text { factor }\end{array}$ & $.59^{* *}$ & .42 & $.59 \times .42 \times 100$ & 24.78 \\
\hline
\end{tabular}

From the above summery we can understand that the contributions of each factor which are included in the research: Personal factor $(12.65 \%)$ Social -cultural factor $(14.25 \%)$ Organizational factor $(24.78 \%)$ from the total of $51.68 \%$ the rest $(48.23 \%)$ which influence women participation on leadership position did not include in the research. And Form the above table it can be seen that organizational factors have the biggest potential to contribute for low participation of women in leadership position following by social culture and individual factor which means the result shown that institutional do not a properly apply or practiced the issued rules, policies, and strategies which women were the top most factors that affect women participation in leader ship position. The social cultural and individual factors were the next most constraints that affect women participation in leadership position.

\section{CONCLUSION AND RECOMMENDATION}

The study findings showed, most respondents believe that organizational factors such that, lack of support from higher officials, inappropriate implementation of rules and regulations, absence of cooperation, mentoring and training, improper budget a location to support women. Lack of giving due recognition for women's performance are major organization problems. The finding shows that from the mean score from there factors that affect women's leadership participation (organizational, socio cultural and personal factor) organizational factor had the largest mean score .Next to this socio cultural and personal factor had the least mean score from organizational and socio cultural factor. This revealed that organizational factor is highly affects women's leadership participation from socio cultural and personal factor. This means the majority of the respondents as organizational factors that largely hinder women career advancement in the governmental organizations.

Similar to the above finding organizational factors also affect negatively in many ways. In other words these factors are related to unfair treatment such as discrimination in selection and recruitment, inappropriate implementation of rules and regulations, absence of cooperation, mentoring and training, improper budget a location to support women. Lack of giving due recognition for women's performance (Ginige et al., 2007).

It is concluded that women's career advancements in governmental organization are not affected by one factor alone but a combination organizational, social, and personal factors. However, according to the majority of the respondents, organizational factors and societal factors seem to have major contribution as compared to personal factors. This study has identified the major barriers that hinder advancement of women to leadership positions 
and hence it has significant implications for promoting gender equality in the leadership positions of governmental organization.

As finding of the study revealed out, still there is low awareness, there, is no proper implementation of women policy, there is no recognition of women for leadership performance, there is no supportive work system for women leaders in the ,organizations do not have continues training. This implies that according to respondent's women leaders have low decision making capacities that cause low participation of women in leadership position, because of organizational factors.

\section{Recommendations}

Based on the findings and conclusion reached the following possible solutions are recommended so as to increase women's participation in leadership.

- The Government needs to make sure that the formulated and ratified specific policies, national objectives, strategies and programs are implemented properly.

- The government needs to take an active part to improve society's awareness to change the deep-rooted cultural believe towards women role by incorporating gender sensitizing courses in the educational curriculum of the educational institutions of the country and by providing short term training for the community

- Society was found to be the major contributor for the underrepresentation of women in leadership, hence societal believe and culture need to be changed towards more clear attitudes through continuous effort and awareness creation

- Women need to educate themselves and broaden their capability so as to break away from the stereotypical behavior.

\section{Recommendation for Further Research}

In this research, information regarding the factors contributing for under representation of women's advancement to leadership positions is identified. However, organizational, the societal, and individuals factors that have impact on women's career advancement are vast and only the main factors within each category were examined in this study. Therefore, further research is required to look into more factors and other organizations in the private sector of the country to arrive at general conclusions and recommendations.

\section{REFERENCES}

Bryman, A. and Bell, E. (2003). Business Research Method, Oxford University press.

Eleny T., (2013). Assessment of Challenges and Opportunities Facing Women Managers in Federal Public Sector. Addis Ababa University, Ethiopia.

FDRE, (1995). The Constitution of the Federal Democratic Republic of Ethiopia, Addis Ababa, Ethiopia

Ginige, K., Amaratunga D. \& Haigh, R. (2007). Gender Stereotypes: A Barrier for Career Development of Women in Construction. Built environment education n conference. University of Salford: Growe,

Hoobler J. (2011), women's under representation in upper management: New insights on a persistent problem organizational dynamics 40, 151-156.

Mbugua, W. (2007). An investigation of factors influencing women progression to leadership positions in Kenya, Kenyatta University.

Netsanet, W. S. (2013). Challenges and opportunities of women to be leaders in selected Governmental secondary schools of Addis Ababa.

Nzomo, M. (1995). Women in top management in Kenya. Nairobi, African Association for Public Administration and Management. 
OSSREA, (2004). Organization for social science Research in Eastern and Southern Africa.

Thornton B. (2012), Women in senior management: international business report.

Willis, V. (1991). "Public Life: Women Make a Difference" Expert group Meeting on the Role of Women in Public Life (Vienna, 21-24 May). New York.

Yukl, G. (2006). Leadership in organizations 6thed. Upper Saddle River, NJ: Pearson-Prentice Hal.

$$
--0--
$$

Publish Online and Print Version Both

Online ISSN: 2312-2021

Google Scholar: https://goo.gl/eozEWi 